Undoubtedly, with every increase in the power of the public health department, a number of physicians have sensed danger to their profession and, from loyalty to their own, have voiced protest. But in every case a group more altruistic, feeling deeper responsibility to the entire community, has advocated the change. In every instance this has come.

During these developments, however, the medical profession has never really suffered. It has protected its own interests by offering much the same service as that of the state. Owing to political conditions, a mass of the public prefers the services of a private physician even in preventive work, while those less fortunate financially are cared for at public expense.

Until recently, preventive medicine has been mainly conccrued with the control of infectious disease. Such problems as infant feeding were too complex and too unsettled to be feasible for organized effort; but the individual study and enthusiasm of the last ten years has revolutionized and decidedly simplified the principles of infant feeding. Diarrheas of obscure and baffling origin, ascribed to every possible hypothetic cause, are now placed as simple dietary failures, too much carbohydrate, too little carbohydrate, lack of vitamin, or improper balance bctween food constituents. Infant feeding becomes relatively simple. With the newer technic, privately endowed infant welfare societies working in a spirit of preventive medicine have shown it practicable to direct the diets of large groups of infants, to keep them happy, healthy and thriving, and to decrease infant mortality by incredible figures. No sooner had this been demonstrated than the state grasped the idea and municipal welfare stations entered the field. Private enterprise is now developing the field of cardiac clinics, and schools are established especially for these patients.

This idea is spreading to the care of adults, and in a rather vague, indefinite way come rumors of health centers and other propaganda for preserving the health of the adult and his ability to work. The state is as yet far from adopting practical measures along these lines. It would seem reasonable to assume that the idea must first be proved practicable hy groups of physicians in private practice. But already another struggle is on. Opponents loyal to the medical profession denounce such tendencies. Their ideals of citizenship rest temporarily on the shelf. Proponents with broader points of view favor another great medical sacrifice so as to bring about intervention for those unfortunates who must pay for efficient service by starvation, and who pay for inefficient skill by suffering and neglect.

Though these ideas have not yet crystallized, the germ is here. If in time to come the public makes such a demand, this demand will be granted. Physicians as a profession or by individual effort may stem the tide, but a democracy will always heed the call of 700 to one.

Is not the time ripe for the physician to look to the future? Must these ideas be thrust on the profession, or will it as in the past be a leader and educator of the layman? Why not give private patients the same benefit as will be offered by the state? Why not offer one's skill and experience not only for the cure of disease but also for its prevention? The pulslic is not blind to such possibilities. The farmer gladly employs means for preserving the health of his cattle and hogs. Corporations employ high salaried attorneys to prevent lawsuits. Every adult goes periodically to the dentist. Why not offer preventive medical service to our patients.

Of all specialties, pediatrics has seized the idea most vigorously. Much of the activity of the modern pediatrician is devoted to keeping his little patient well. In introducing such ideas the physician finds enthusiastic cooperation. The mother is delighted in an interest which attempts to preserve fier child's health. She gladly consents to routine examina- tions that aim at prophylaxis. She is well satisfied to understand that orange juice, cod liver oil, phosphorus, calcium and iron are given at various times with a vicw of preventing disturbances rather than of curing them. Indeed, this idea, first conceived with regard to the nutritional disturbances, meets with such a welcome that by one's own practice one is almost forced into other fields. Smallpox vaccination, of course, is not new. The recent bealth department propaganda has resulted in a bombardment of questions as to the advisability of giving toxin-antitoxin mixturc. Typhoid vaccination is well established. Mothers literally insist on prophylactic injections of pertussis vaccine in spite of the warning as to its doubtful efficacy.

Granted examinations at stated intervals, routine supervision of the diet, and prophylactic procedures as regards infectious disease, a children's practice becomes a source of great satisfaction and pleasure. Such work is the finest feature of the day's duties.

Is not the time ripe for the general practitioner to offer in an organized way some such service to adults? Such a slight adaptation to the demands of the present would mean much to the general public and to the physician as well. One might truly feel that he was entering a new era. "State medicine" might grow in influence and no cloud darken the medical horizon. The altruistic activities of the physician would be compatible with professional livelihood. He himself would prosper in attempting to actualize his abstract dreams. Medical ideals harmonizing with medical prosperity would thrive in an atmosphere of hcalth and happiness.

Jesse R. Gersteey, M.D., Chicago.

\section{THE MICHIGAN STATE MEDICAL SOCIETY AND THE MEDICAL SCHOOL OF THE UNIVERSITY OF MICHIGAN}

To the Editor:-During the past years, and especially through this last year, rumors and misstatements have appeared in the medical as well as the lay press. They were concerned with compulsory health insurancc, "state medicine," socialization of medicine, administrative policies of the Medical School of the University of Michigan, and the antagonism of the medical profession of Michigan.

Jan. 11, 1922, in Detroit, the council of the Michigan State Medical Society, and President Burton and a committee of the University of Michigan met in conference. As a result of that conference, we desire to make the following announcements to the profession and public of this country over our signatures:

1. A basis of mutual understanding has been reached, and past apparent differences have been obliterated.

2. The university and its medical school are not in favor of "state medicine," so called, nor do they indorse or subscribe to those policies or movements that have for their object the establishment of any such forms for the practice of medicine.

3. Dr. Hugh Cabot, dean of the medical school, has been and is opposed to "state medicine." so called. He desires his opposition to be known to the entire profession, and that in the past he has been unjustly accused of being favorable to that type of socialization of medical practice.

4. In response to the invitations of the president and council of the Michigan Medical Society, the University of Michigan, througli its extension division and medical school, has expressed its desire and readiness to educate the public in regard to scientific medicine and the benefits to be derived therefrom.

5. The medical school is concerned chiefly with the education of students in scientific medicine, with the promotion of 
medical research, and with cooperation with the profession in the advancement of scientific medicine in Michigan.

To these ends have we pledged ourselves and through duly appointed representatives we propose to enter into a campaign of concerted and cooperative activity. Coincident with this action, we believe that the profession at large should be acquainted with our avowed attitude. We therefore issue this statement at this time for the explicit purpose of discrediting false assertions of the past and to make clear for the future the policies and purposes of the principals concerned in this announcement.

\section{The Michigan State Medical Society: \\ W. J. KAX, President, \\ W. J. Du Borse, Chairman of the Council. \\ The U'Niversity of Michigan : \\ Marion L. Burton, President, \\ Hugh Cabot, Dean of the Medical School.}

\section{"CIRCUMCISION PREVENTS SYPHILIS"}

To the Editor:-In THE Journal, Aug. 27, 1921, appears an abstract of an article in the Virginia Medical Monthly by Irvine, who asserts that nation wide circumcision would practically stamp out syphilis in a few years. I have not seen the article itself so that I do not know what arguments the author adduces; but if his claim is true, it would follow that syphilis should be very rare among Mohammedans and Jews, both of whom practice circumcision as a religious rite. What the statistics of syphilis among Jews in America is compared with other races I do not know; but the disease is frightfully common in Persia among both Mohammedans and Jews. The impression derived from ten years of practice of medicine in Persia is that syphilis is much more in evidence than in America, and that its incidence is steadily and rapidly increasing. As practically all the male population of Persia is circumcised, this evidence would seem to disprove the value of circumcision as a prophylactic measure.

M. A. Zoeckler, M.D., Daulatabad, Malayir, Persia.

\section{"THE MODE OF PRODUCTION OF THE SO-CALLED VESICULAR MURMUR OF RESPIRATION"}

To the Editor:-I have read with much interest Dr. Bushnell's article on vesicular murmur (The Journal, Dec. 31, 1921 , p. 2104), and it would seem to me that his conclusion that the sound of inspiration arises or originates in the larynx from a common sense standpoint is not well founded.

If we are to assume that the normal murmur arises in the larynx during inspiration, why should we not be warranted in also assuming that bronchovesicular breathing and even sonorous râles originate in the same manner? This assumption would upset our present interpretation of physical signs.

\section{H. F. Gammons, M.D., Dallas, Texas.}

[This letter was referred to Dr. Bushnell, who replies:]

The difficulties will, I think, be removed if it is noted that I say that the breath sounds originate in the larynx. My paper states distinctly that the sounds of vesicular and of bronchial breathing, as we hear them over the thorax, owe their characteristics to the thorax and to the bronchi, respectively. But these air-spaces function as resonators and, like other resonators, do not originate sound; they reinforce existing sounds of proper pitch. Therefore, when the larynx is silent the thorax also is silent. It is only in this way that we can reconcile two facts: first, the undoubted fact that the vesicular murmur has been heard under conditions in which the voral cords are excluded; second, the fact, which I con- sider to be established, that when the glottis is opened widely enough the vesicular murmur disappears. While this view throws a very different light on the mode of production of both normal and alnormal breath sounds, I do not see that it affects materially the interpretation of physical signs. The vesicular murmur, as we hear it; is still caused by the vibrations of the air within the pulmonary alveoli, and the sounds of bronchial breathing are still produced in the bronchi.

I have, of course, no belief that the larynx has any part in the production of sonorous, or other, râles.

$$
\text { G. E. Bushneld, M.D., Bedford, Mass. }
$$

\section{Queries and Minor Notes}

Anonymous Communications and queries on postal cards will not be noticed. Every letter must contain the writer's name and address, but these will be omitted, on request.

\section{VIBRATIONS OF MUSICAL TONES}

To the Editor:--Please inform me as to the number of double vibra. tions per second for the octave of musical tones as listed: $c^{2}(512 \mathrm{~d} . \mathrm{v}$.) $c^{2}$ sharp, $d^{2}, d^{2}$ sharp, $e^{2}, f^{2}, f^{2}$ sharp, $g^{2}, g^{2}$ sharp, $a^{2}, a^{2}$ sharp, $b^{2}, c^{3}$ (1,024 d. v.). J. N. Stoops, M.D., and R. P. Stoops, M.D.

Scottsbluff, $\mathrm{Neb}$

Axswer.-The vibrations of musical sounds are of particular interest to otologists. The number of double vibrations per second in the octave mentioned are:

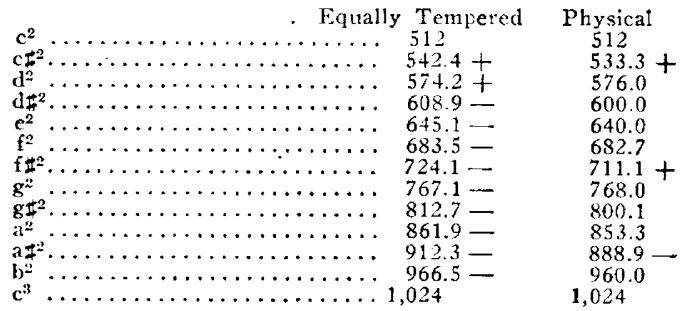

The ratios of the notes of the major diatonic scale are with respect to the keynote: $1,9 / 8,5 / 4,4 / 3,3 / 2,5 / 3,15 \%, 2, \mathrm{~B}_{y}$ multiplying the vibrations per second of the keynote by these ratios, respectively, the vibrations per second may be obtained for each of the notes of such scale. This is the exact physical scale. In order to obtain the vibrations per second of the sharp of any note, multiply by $25 / 24$. In order to obtain the vibrations per second of the flat of any note, multiply by $24 / 25$. The sharp of $\mathrm{c}^{2}$ and the flat of $\mathrm{d}^{2}$ do not agree, and therefore in order to make a keyboard which it was possible to use, a scale called the "equally tempered scale" was invented and is now used in virtually all music.

In order to obtain the vibrations per second of any note on the piano, multiply the vibrations per second of the preceding note by $\sqrt[12]{2}$. This applies for the complete chromatic scale. However, the pitch 512 vibrations per second is not used on the piano. International pitch uses 517.12. Assuming 512 to be correct, the other values are given above.

\section{ACETIC ETHER AS A PEDICULICIDE}

To the Editor:-Please summarize briefly the "Safe and Quick Acetic Ether Method of Getting Rid of Head Lice," as recommended by Dr. Walter Schnell in the Dettsche medizinische Wochenschrift 47. 125 (Oct. 20) 1921, and mentioned in The JournaL, Jan. 7, 1922, p. 76 Francis Schill, JR., M.D., Johnstown, $\mathrm{Pa}$.

Axswer.-For the application of acctic ether (ethyl acetate) to rid a subject of head lice, Schnell recommends a special type of hood, which, while fitting the head tightly at the outer border, so as to prevent the escape of vapors, has a roomy crown with sufficient space for the hair to hang loose, thus permitting the fumes of ethyl acetate to penetrate to all parts of the head. On a thin layer of absorbent material (artificial cellulose), from 5 to 10 c.c. of ethyl acetate is distributed as evenly as possible over the hairy scalp, whereupon the hood is immediately applied and drawn tight across the forehead by a band of porous material within the hood and tied behind the head, while another band beneath the chin secures the lower portion. The lice are usually all killed at 